\title{
Eternalist Theories of Persistence Through Time: Where the Differences Really Lie
}

\author{
Jiri Benovsky
}

Received: 15 October 2008/ Accepted: 12 November 2008/Published online: 3 December 2008

(C) Springer Science+Business Media B.V. 2008

\begin{abstract}
The eternalist endurantist and perdurantist theories of persistence through time come in various versions, namely the two versions of perdurantism: the worm view and the stage view, and the two versions of endurantism: indexicalism and adverbialism. Using as a starting point the instructive case of what is depicted by photographs, I will examine these four views, and compare them, with some interesting results. Notably, we will see that two traditional enemies - the perdurantist worm view and the endurantist theories-are more like allies: they are much less different than what is usually thought, and some alleged points of central disagreement fall prey to closer scrutiny. The aim of this paper is to examine carefully all those points, and to call attention to the places where the real differences between these views lie. I will then turn to the perdurantist stage view, and claim that with respect to some central issues it is the view that is the most different from the other three, but that in some places the reason why it different is also the reason why it is less satisfactory.
\end{abstract}

Keywords Perdurantism $\cdot$ Endurantism $\cdot$ Persistence through time $\cdot$ Eternalism

\section{Introduction}

\subsection{Point 1}

When looking at a photograph, one who is not familiar with photography may have the naïve impression that it depicts ${ }^{1}$ an instantaneous part of reality-a 'frozen'

\footnotetext{
${ }^{1}$ I use "depict" roughly in the sense of what a photograph represents; and I use it neutrally with respect to the debate concerning questions about whether photographs depict something in the same way paintings do.
} 
moment of the world. But of course, this is not so, since taking a photograph takes time, even if often a very short one, and a photograph thus depicts not an instant but an interval of time. While the naïve mistake is an easy one to make with respect to, for instance, holiday landscape photographs that are usually taken at a high shutter speed, the error becomes easily apparent on photographs that include moving subjects where the exposure time is longer, such as on the photograph below (2.5 s shutter speed):

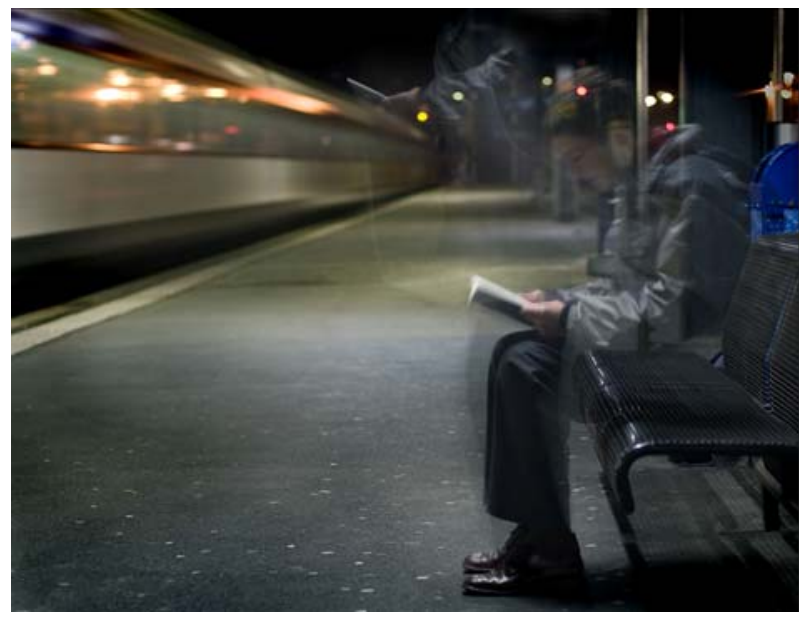

On photographs such as this one, the point appears obvious: it depicts a temporally bigger portion of reality than just an instant of it. In this paper, I will use the case of photographs to raise a discussion about some general points (independent on photography) concerning eternalist theories of persistence through time, and I will start by asking: "what kind of entities are depicted by photographs?" Plausibly enough, they depict events, but they also depict objects (a person, a building, a bench ...), and it is the latter that I am interested in here. Given that the objects depicted by photographs, which I will call the 'depicta', are represented as something that persists (and changes!) through the whole interval of time depicted by the photograph, a discussion of theories of persistence through time is indeed here relevant, and as we shall see the case of the depicta of photographs is an illuminating case that will shed some light on certain interesting features of these theories.

Due to concerns about the length of this paper, I will limit myself here to the case of eternalist theories of persistence (I discuss the case of presentist theories in my manuscript). Eternalism is the doctrine about time which takes future and past objects to exist in the same way present objects do-there is no ontological difference between past, present and future; as Ted Sider puts it: "Just as distant places are no less real for being spatially distant, distant times are no less real for being temporally distant" (Sider 2001a, p. 11). In the eternalist's manner of speaking, future objects "exist", as well as present objects exist, in an atemporal sense of the verb; it is as if one were viewing the universe from a God's standpoint and could contemplate all that happened, happens and will happen laid before his 
eyes (Arthur Prior calls this "the tapestry view of time" Prior 1996, p. 47). On this view, "now" is an indexical term as well as "here" is.

\subsection{Point 2}

The endurantist and perdurantist theories of persistence through time come in various versions, namely the two versions of perdurantism: the worm view and the stage view, and the two versions of endurantism: indexicalism and adverbialism. Using as a starting point the instructive case of the depicta of photographs, I will examine these four views, and compare them, with some interesting results. Notably, we will see that two traditional enemies - the perdurantist worm view and the endurantist theories - are more like allies: they are much less different than what is usually thought, and some alleged points of central disagreement fall prey to closer scrutiny. The aim of this paper is to examine carefully all those points, and to call attention to the places where the real differences between these views lie. I will then turn to the perdurantist stage view, and claim that with respect to some central issues it is the view that is the most different from the other three, but that in some places the reason why it different is also the reason why it is less satisfactory.

\section{Part I: The Perdurantist Worm View and Endurantism: Enemies or Allies?}

\subsection{Point 3}

Let us start with the worm view. One way to present it, and a way that will be useful to my purpose here, is to see how it handles the phenomenon of intrinsic change through time. Take the case portrayed on the photograph above of a man, Sam, sitting on a bench and reading a book from $t_{1}$ to $t_{3}$ and then, at $t_{4}$, standing up and walking away. Sam, then, not only persists through the times from $t_{1}$ to, say, $t_{6}$ but he also undergoes intrinsic change-he is first bent (since he is sitting) and then straight (when he stands up), as illustrated on the figure below:

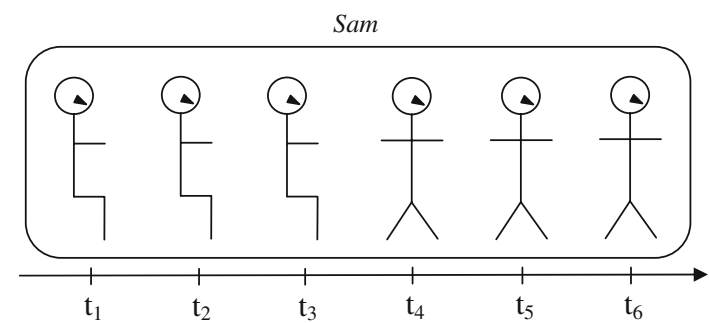

Worm view theorists claim that Sam is a 'space-time worm', that is, a temporally extended entity that has temporal parts at every time at which it exists, and that his having of different incompatible properties at different times is a matter of him having different temporal parts at different times that have simpliciter the incompatible properties. 
Now, suppose that the photograph of Sam above, taken at a low shutter speed, depicts him during the interval from $t_{2}$ to $t_{5}$. What is then the depictum of the photograph? Easily enough, the worm view theorist can say that the photograph depicts a sub-worm of Sam, that is, a space-time worm that is just temporally smaller than Sam-a non-instantaneous temporal part of Sam:

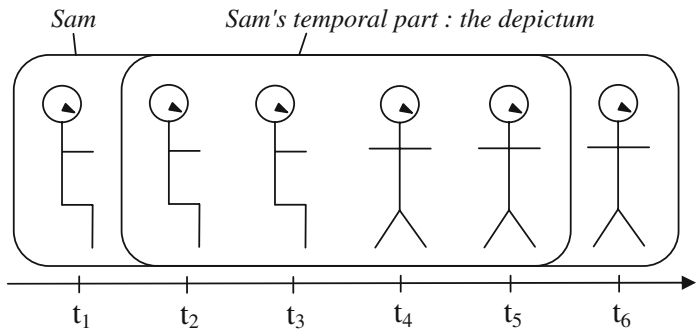

On the photograph, Sam appears blurred, fuzzy, and partially transparent, this is because, roughly, the first half of his temporal part depicted by the photograph, the sitting one, only occupies a half of the interval and, thus, only a half of the total exposure time, which makes it then appear half-transparent on the resulting photograph; and similarly for his other temporal half.

None of the above yields any difficulties as far as the worm view is concerned. According to the worm view, people are temporally extended worms that have temporal parts, and qualitative intrinsic change over time is handled in terms of the having of qualitatively different temporal parts at different times. An entity to play the role of the depictum of a photograph such as the one of Sam is thus easily provided by the worm view's ontology: a space-time worm, as Sam is, just temporally smaller. (I am not saying, of course, that the worm view is objectionfree; all I am saying is that given the worm view, there are no worries with respect to the nature of the depicta of photographs.)

\subsection{Point 4}

The case of endurantism is more complex. Endurantism is often put as the view that says that an object persists through time by being wholly (and not partly, as the worm view has it) multiply located at all times at which it exists. Thus, at first, one might be tempted to draw the following schema:

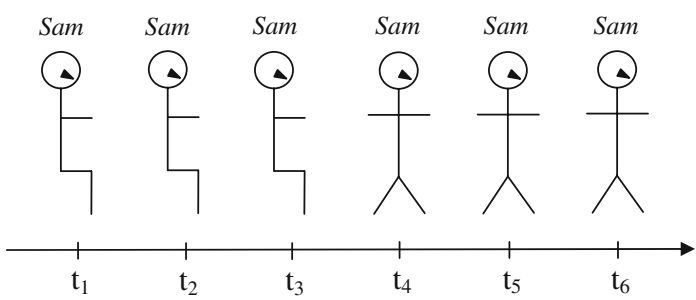

With respect to the question about the depicta of photographs, there seems to be a bizarre prima facie answer: a photograph of a person (even an 'ordinary' one, taken 
at a high shutter speed, where nothing is blurred) depicts one person a lot of times (infinitely many times, if time is continuous). This sounds a bit strange, for the same reason this whole picture of endurantism is strange: given eternalism, the idea here is that time is space-like-but try to imagine the analogous spatial case of an object 'multiply located' at a lot of places in your garden at the same time. Clearly, since objects are not universals, the natural thing to say here would rather be that there are different objects laid before one's eyes in the garden and not one single object multiply located at all those different places. And since eternalism takes time to be like space, if the picture above were the correct endurantist picture, the view would be as strange as this spatial case.

But, fortunately, it is a bad picture. To see why, let us make a detour and consider a traditional objection raised against endurantism, and see how endurantists reply to it: the objection from temporary intrinsics. According to endurantism, Sam at $t_{1}$ is numerically identical to Sam at $t_{5}$. At $t_{1}$, he is bent, at $t_{5}$, he is straight. But if we follow the principle of Indiscernibility of Identicals, if Sam at $t_{1}$ and Sam at $t_{5}$ are numerically identical then they should have all the same properties. But this leads to the untenable claim that Sam, the very same object existing at $t_{1}$ and $t_{5}$, has the two incompatible properties of being bent and being straight. This objection-that endurantism fails to give an account of how persisting objects can have incompatible properties at different times — was raised by David Lewis who once considered it to be "the principal and decisive objection against endurance" (Lewis 1986, p. 203). ${ }^{2}$

To avoid the contradiction resulting from Sam's having the incompatible properties, the perdurantist worm view is revisionary about the object that exemplifies those properties by analyzing it as an aggregate of temporal parts. There is no risk of contradiction here because the incompatible properties are had by different things, different temporal parts of Sam that are not claimed to be numerically identical.

A first way ${ }^{3}$ for endurantists to reach the same result is Peter Van Inwagen (1985)'s way which is revisionary not about the object but about the properties. To avoid contradiction, it is enough to say that properties are always time-indexed and that consequently Sam does not exemplify two incompatible properties such as "being bent" and "being straight", rather he has the time-indexed properties "being-bent-at- $t_{1}$ " and "being-straight-at- $t_{5}$ " which are perfectly compatible.

Typically, perdurantists will object that, while it is true that there are time-indexed properties, there still also are non-indexed properties like "being bent" and that the contradiction has not been avoided, because even if Sam has at different times noncontradictory time-indexed properties, it is also, and most importantly, possible for him to have the non-indexed properties - and so trouble has not been avoided.

But this latter line of argument is quite strange, for it commits one to the claim that Sam's having of a property is his having of it simpliciter without any disguised relations to times being involved. This is a strange strategy here because, while it is true that endurantism cannot accommodate this claim, the perdurantist worm view does not accommodate it either, since it also achieves Sam's having his properties only via a temporalizing device: Sam, the temporally extended object, is not bent, he

\footnotetext{
2 Compare Lewis (2002) for this and below.

3 The adverbialist strategy will be discussed in Sect. 2.6 below.
} 
can only be said to have this property at a time, by having a temporal part that has it. So neither endurantism nor the worm view (tu quoque!) can defend the claim that Sam has his temporary intrinsic properties simpliciter. ${ }^{4}$ (Perdurantists often say that Sam has his properties in a "derivative" way.) So, the worm view temporalizes objects (temporal parts), while endurantism temporalizes properties, and despite Lewis's objecting to the use of temporalized properties, and Van Inwagen's objecting to the use of temporalized objects (see for instance Van Inwagen 1985, p. 194), it just seems here that both views use a theoretical temporalizing device that plays the same theoretical role of making it possible for Sam to have properties; more precisely, the device "to be a $t_{n}$-part of" plays here the same role here as the device "-at- $t_{n}$ ".

The moral of the considerations above is twofold. First, both endurantism and perdurantism use a theoretical temporalizing device in order to avoid the threat of contradiction from the having of temporary intrinsic properties, and so, not only endurantists should be allowed to use their temporalizing device by their opponents, but also we have just made a very first small step towards the claim that the difference between endurantism and perdurantism is perhaps not as big as one would initially think. Second, here is the correct endurantist picture: ${ }^{5}$

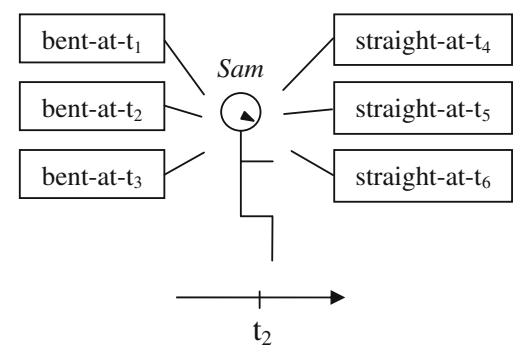

If $t_{2}$ is the present time, Sam is pictured as being bent, but he also has all of his time-indexed properties - indeed, he has them all at all times at which he exists. The latter point constitutes a further step towards the idea that endurantism and the worm view are not that different. To see why, let us consider a traditional objection to the worm view: the 'no-change objection'.

We have seen above how the worm view provides a nice and elegant treatment of how objects have different (incompatible) properties at different times-that is, how objects can undergo change over time. But this nice and elegant solution is sometimes criticized. Some will say, following, among others, Peter Simons that the "four-dimensional (i.e., worm view) alternative is not an explanation of change but an elimination of it, since nothing survives the change which has the contrary properties" (Simons 2000, p. 64). We want to give an account of how a single object, Sam, can persist through change and the perdurantist is here telling us a story about different objects (different parts) having different properties, and this is not the story we wanted to be told. Once it is true that a certain temporal part of Sam is

\footnotetext{
${ }^{4}$ Granted, and close to Lewis' heart, only the perdurantist worm view allows for something (but not Sam) to have temporary intrinsic properties simpliciter, namely, temporal parts of Sam. I will come back to this at the end of Sect. 2.5 .

5 See Van Inwagen (1985).
} 
bent, it will always be true-this is a fact that cannot, according to the worm view, change. And this is what leads some to call this view a 'static' ontology: everything seems to be just there and no object can ever genuinely change.

It is not my aim here and now to explore the worm view theorist's reply to this objection-it will be done in Sect. 3.1 below when I will discuss the stage view. Rather, the very simple point that I want to make now is that the objection applies in exactly the same way to endurantism. Even for the endurantist, the fact that Sam has the property of being-bent-at- $t_{1}$ is eternally (always) true and can never change. Since all properties, according to endurantism, are time-indexed, any property that Sam has, he has it always and forever, and so he has at $t_{1}$ the very same properties that he has at $t_{5}$, and so, the 'no-change objection' goes, he does not undergo genuine change.

As in the case of the worm view, I do not think that this is something that should bother the endurantist at all (for more details see Sect. 3.1 below). Change is the having of different properties at different times, and both views manage to secure this claim. But this is not my point here. The claim that I want to make is simply that if the 'no-change objection' applies, it applies equally to both views; and if it does not apply, it does not apply to either of the two views. Exactly as the case of temporary intrinsics seen above was supposed to be an objection to endurantism and a reason to favour the worm view, but is not, the case of the no-change objection was supposed to be an objection to the worm view and a reason to favour endurantism, but is not. Either both views are guilty of it or neither is. (More precisely, the guilty guy, if anyone is guilty here, is eternalism.)

This completes the second step of my case for the claim that the perdurantist worm view and endurantism, instead of being deadly enemies, are actually quite close one to each other. Let us continue.

\subsection{Point 5}

Now that we have the correct endurantist picture in mind, we can ask how it handles the case of the depicta of photographs. Remember that the photograph of Sam in Sect. 1.1 was taken at a low shutter speed and that it depicts him during the interval of time from $t_{2}$ to $t_{5}$. So, something more needs here to be said in addition to the endurantist picture, since this picture only represents Sam at one time (namely $t_{2}$, in the example above). Indeed, Van Inwagen insists that the features (relevantly, being bent) portrayed on the schema should be those that Sam has at the present time, while his other properties are only represented as being exemplified by Sam, but not as being drawn on the schematic image. This may well work in the idealized case of an instantaneous present time, but it will not do for the case of photographs, since they never depict an instantaneous part of reality. When drawing such a schema for the photograph of Sam, we would easily know what properties we should fill in the boxes (that is, all of his time-indexed properties that he ever has), but we would not know how to draw the schematic image of the person and how to draw the arrow of time, while avoiding to end up with the bad endurantist picture we have seen at the beginning of Sect. 2.2. But don't worry, this is no trouble at all, one just needs to be more precise.

By "being more precise", I mean to stop drawing schemas in terms of little fellows sitting or otherwise, but by being a bit more abstract and representing on the 
schema the fundamental components of the nature of Sam. Namely, there are two main options: Sam is a bundle of properties, or Sam is a bare particular (substratum) that instantiates properties. ${ }^{6}$ Let us start with the bundle theory:

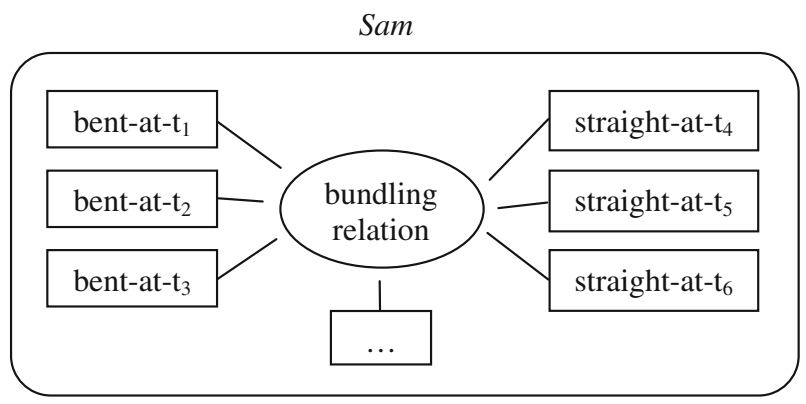

According to this eternalist endurantist indexicalist bundle-theoretic view, Sam is a bundle of properties (all of his time-indexed properties) united by a special primitive relation often called "compresence" or "consubstantiation"-I shall simply call it "the bundling relation" in order to have a label as neutral as possible and as non-informative as possible since this relation is a primitive one that is only defined by its theoretical role: bundling together properties in order to make particulars. Now that we have this more precise picture in mind, we can ask how it provides an account of what is being depicted by the photograph of Sam. Here, the answer is as easy and straightforward as it was in the case of the worm view (it just took more time to get there in the endurantist's case not because endurantism handles this phenomenon less well, but because endurantism needed to be articulated more carefully in order to have a view precise enough to be able to do any good job): it depicts a part, a 'sub-bundle', of Sam who is the whole bundle. Since the photograph depicts the interval of time between $t_{2}$ and $t_{5}$, it depicts the sub-bundle of Sam that includes all of his properties that are indexed between $t_{2}$ and $t_{5}$.

There is nothing special coming from the bundle theory here, since the same treatment can be given if one embraces the substratum theory as well:

Sam

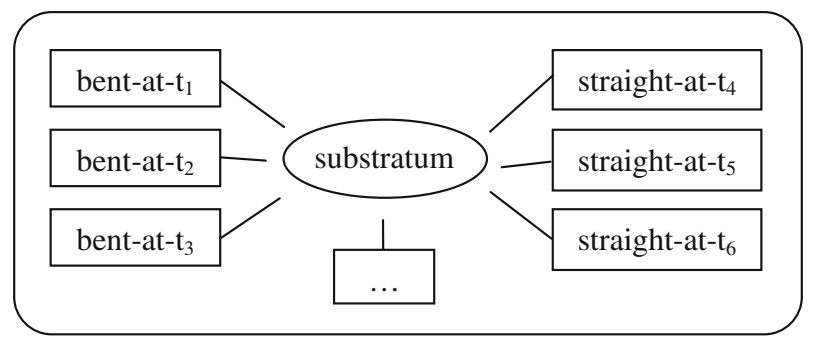

\footnotetext{
${ }^{6}$ Given the purposes, the scope, and the length of this paper, I unfortunately cannot examine all possible variants of these two views, and I will limit myself to the general way they work, which will be enough for what I want to claim. I will also ignore in this paper the 'substance' theory (for the same reasons as those just given, and because I think it does not work at all, for reasons entirely independent on the debate I am interested in here).
} 
According to the substratum (or 'bare particulars') theory, Sam is not only a bundle of properties, rather his properties inhere in a substratum that exemplifies them and unifies them in order to make a (thick) particular. But, with respect to my present concerns, it does not matter whether it is a substratum that unifies the properties in order to make a particular, or whether they are united by the bundling relation. ${ }^{7}$ Both views get rid of the problem of not knowing how Sam should be drawn (bent or straight?), since neither the substratum nor the bundling relation have to be conceived that way, and both views get rid of the arrow representing the flow of time, since all the information provided by it is already given by the indexes attached to the properties. Both views are thus structurally entirely similar, and allow for the same treatment of the nature of the depicta of photographs-in the case of the bundle theory it is a sub-bundle, a part ${ }^{8}$ of the bundle that Sam is, and in the case of the substratum theory it is a part of the whole of Sam as well: the substratum plus all of the properties that are indexed between $t_{2}$ and $t_{5}$.

One way to see that this part of Sam is a genuine object in its own right is to imagine a case where the remains of Sam do not exist-for instance, a case where a person qualitatively exactly like Sam is created ex nihilo at $t_{2}$ and destroyed at $t_{5}$ in such a way that it exists just for the interval of time where the photograph is taken. The photograph would then depict this short-lived person that is not part of any (temporally) bigger person-and so we see that the temporal part of Sam that occupies the interval between $t_{2}$ and $t_{5}$ 'does not need' the remaining temporal parts of Sam in order to count as an object.

The upshot of all these considerations is the following: first, endurantists can handle the case of the depicta of photographs as easily as perdurantists, and second, more importantly since the case of photography is no more than a particular illuminating example, the general and more important truth is that the difference between the perdurantist worm view and endurantism is getting smaller and smaller. Indeed, contrarily to what is usually said by both opponents of endurantism and by endurantists themselves, both views implement the notion of a temporal part of objects such as Sam.

This is news, and it is good news for the endurantist, since now she can answer some of the strongest objections that were raised against it, namely those that arise from apparent cases of coincident entities such as the case of the Statue and the Lump Sider's (2001a) "Four-dimensionalism" is among the very influential places where this objection is drawn). So, let me now show how endurantists can avoid this sort of objections.

\footnotetext{
7 See my Benovsky (2008) for a detailed comparison between the bundle theory and the substratum theory-a place where I argue in favour of an equivalence between (some variants of) these two views.

${ }^{8}$ Laurie Paul in her defence of the bundle theory speaks about "logical parts" here, and defends a genuine property mereology (Paul 2002). In Paul 2006 (especially Sects. 2.2 and 2.3) she develops in detail the idea that ordinary objects are qualitative fusions that have properties as parts, and explores the interesting consequences this has on the problem of coincidence; what I say about the Statue and Lump case below is a simplified version (that is sufficient for my purposes in this paper) of the same basic idea that she discusses brilliantly in more depth.
} 


\subsection{Point 6}

Let us say that at $t_{1}$ there is a lump of clay that at $t_{2}$ an artist forms into a statue. Thus at $t_{2}$ a statue is created. Let us say that it persists until some later time $t_{3}$ and is then destroyed (squashed). At some time after its destruction, at $t_{4}$, the statue of course does not exist anymore but the lump of clay still does. The lump of clay persists from $t_{1}$ to $t_{4}$ : it existed at $t_{1}$ in a certain (let us say cubic) form, then it was shaped into the form of a statue and, after the destruction, it was shaped again into some other squashed form. A puzzle arises here because it seems that in the interval of time from $t_{2}$ to $t_{3}$, the lump of clay and the statue are one and the same object: they have the same form, the same location, they are made up of the same particles. But, if they were the same object, they should, according to the principle of Indiscernibility of Identicals, share all their properties. But this is not the case: the lump of clay has, for instance, the historical property of being cubical at $t_{1}$ that the statue has not. So, after all, the statue and the lump of clay are different objects. But then, it seems that we have a strange situation where we have two distinct objects that coincide between $t_{2}$ and $t_{3}$. But how can that be? How can two different objects be made of the same particles, have the same spatial location, etc? As Lewis asks, if the lump weights $500 \mathrm{~g}$, and the statue weights $500 \mathrm{~g}$, and if both objects are there between $t_{2}$ and $t_{3}$, why don't we have in this interval of time something that weights $1,000 \mathrm{~g}$ ? It seems that coincident objects are just unacceptable.

To provide an account of this case while avoiding the commitment to coincident objects, the worm view theorist has a simple reply. The $t_{2}$-part and the $t_{3}$-part of the statue are numerically identical, respectively, to the $t_{2}$-part and the $t_{3}$-part of the lump of clay. For instance, the $t_{2}$-part of the statue and the $t_{2}$-part of the lump of clay do share all of their properties-relevantly, they don't have any different historical properties such as being cubic at $t_{1}$ because none of them existed at $t_{1}$. But, of course, this does not entail that the statue and the lump of clay (the worms) are identical: the lump of clay, for instance, has parts at $t_{1}$ while the statue does not. So they are not identical but they share identical temporal parts-they temporally overlap. Thus, if we accept temporal parts, the puzzle with the 'coincident' statue and lump of clay is no more remarkable than the spatial case of two overlapping roads, one of them being a sub-segment of the other (see, among others, Sider 2001a, p. 6, 152), as the following figure illustrates.

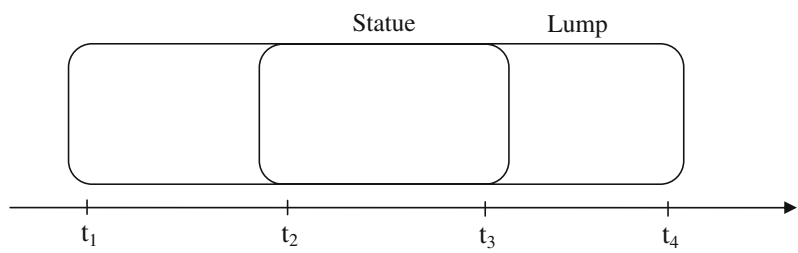

For the endurantist, however, the puzzle is traditionally taken to be genuine trouble. Since it is the entire statue, and not a part of it, that is wholly present at $t_{2}$ or $t_{3}$, since the same holds for the lump of clay, and since they are distinct objects because they do not share all of their properties, the endurantist must endorse the claim that, between $t_{2}$ and $t_{3}$, two numerically distinct objects coincide (see the 
figure below). Such a claim being unacceptable, this puzzle provides the objector with a reductio against endurantism.

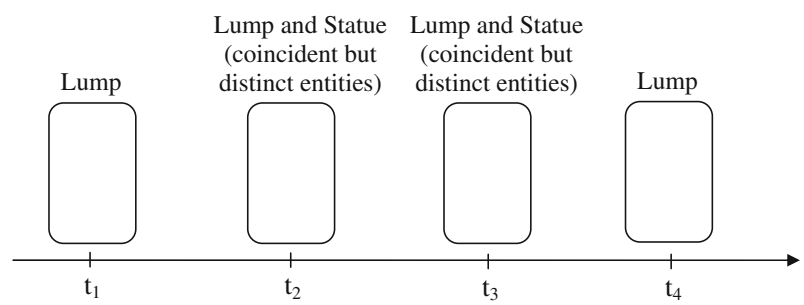

But now, let us benefit from our lessons about bad pictures, and let us see what the situation really is (I shall use below schemas using the bundle theory, but in the same way as above, it would not make any difference relevant to my present concerns to use the substratum theory). Let us have the following properties: $\mathrm{CS}=$ "being cubeshaped", SS = "being statue-shaped", BS = "being blabla-shaped" (squashed), $\mathrm{W}=$ "weighting $500 \mathrm{~g}$ ". The perdurantist picture is then the following:

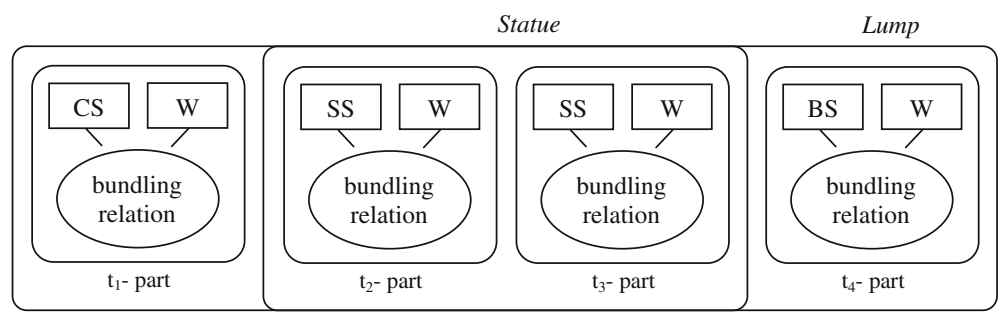

Nothing very exciting. The bundle Statue is simply a sub-bundle of the bundle Lump. This is how, in terms of the bundle theory, we have the notion of overlap used above by the perdurantist to answer the objection. The endurantist (good) picture is more interesting:

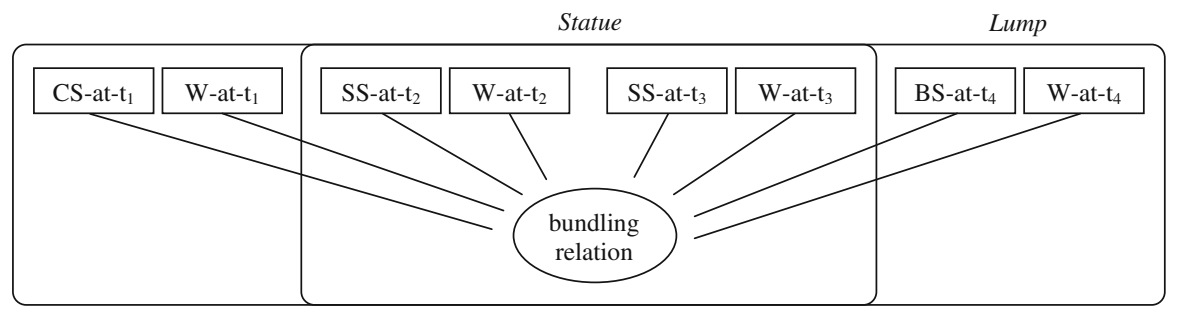

This picture provides a nice surprise for the endurantist: she has readily at hand here the very same nice treatment of the case that the perdurantist has. Exactly as in the worm view view, the bundle Statue is a sub-bundle of the bundle Lump. So, as in the case of the perdurantist worm view, we have the same notion of partial overlap. This notion gives us, in both the perdurantist and the endurantist case, the means to talk about two objects (if you want you can say two "coincident" objects, but they are not coincident in any weird or unacceptable way, there are two objects in the nonobjectionable sense in which there are two objects where there is a common part of 
two Siamese twins), but also to talk about one object (the common part of the two Siamese twins is one). So, both views can equally well and happily accept talk of two objects and talk of one object in a non-objectionable way. The endurantist can simply help herself with the same strategy the worm view has been using all along.

Generalizing, we can conclude that both views have the same explanatory power with respect to the puzzle cases involving coincidence, and this completes another important step towards the claim that the difference between endurantism and perdurantism is much smaller than what is usually thought.

\subsection{Point 7}

What exactly is the conclusion of my overall argument? We have gone through four steps:

1. Both views have to use a temporalizing device ("to be a $t_{n}$-part of" and "-at$\left.t_{n}{ }^{\prime \prime}\right)$ in order to be able to say that Sam is bent or straight, and none of them can say that Sam is bent or straight simpliciter.

2. Both view have to (and can) equally face the 'no-change objection'.

3. Both views implement the notion of a temporal part (and can thus handle the case of the depicta of photographs in the same way).

4. By using the notion of a temporal part both views can equally well provide a satisfactory treatment of puzzle cases involving coincidence such as the Statue and Lump case.

All of the four steps above were supposed to constitute the main differences between the two views, and all four have even been considered as being decisive in favour of one of the views over the other. (To provide only one reference for each step: Lewis (1986, p. 203) at one point thought that (1) was decisive against endurantism; Simons (2000, p. 64) thinks that (2) is decisive against perdurantism; Van Inwagen (1981, p. 90) thinks that (3) is decisive against perdurantism since the notion of a temporal part is unintelligible; Sider (2001a, Chap. 5) thinks that (5) is decisive against endurantism.) So, if these four central points of alleged disagreement between the two views collapse, doesn't it in the end turn out that there is no difference at all between the two views, and that they only are some sort of terminological variants of each other? No, for two genuine differences remain. First, as we have seen in (1) above, neither the worm view nor endurantism can say that Sam is bent or straight simpliciter, but only the worm view can say that something is bent or straight simpliciter, namely, one of his momentary temporal parts (see for instance the last perdurantist schema in the previous section). Second, once we have in mind the precise pictures (let them be bundle-theoretic or using the substratum theory, it does not matter here), it is easy to see that the two views are structurally different, for instance, if you take the case of the substratum theory, the worm view will claim that there is one substratum per time that unifies the properties had by Sam at that time, while the endurantist view will claim that there is one substratum only that unifies all of the properties of Sam that he ever has (and this makes for the endurantist claim that objects persist through time by being numerically identical at different times, while the former makes for the perdurantist 
claim that nothing is ever numerically identical at different times and that objects persist through time by having temporal parts). These two differences between the two views are related: only because of their different structure can there be a difference in the way the two views can or cannot claim that something has properties such as being bent simpliciter. This is then where the differences between these two traditional enemies lie, and not in one of the claims under (1-4).

\subsection{Point 8}

In Sect. 2.2 I postponed the discussion of the version of endurantism called 'adverbialism', and in the preceding sections I examined the endurantist view that embraces indexicalism as a strategy to face the Lewisian worry from temporary intrinsics. I shall now more quickly go through the adverbialist strategy, to see that the same conclusions as above can de drawn for this version of endurantism as well.

Adverbialism is a version of endurantism that as a solution to the problem of temporary intrinsics suggests not to temporally modify the property but the having of it. Thus the adverbialist will say that "Sam is bent at $t_{1}$ " is to be analyzed as "Sam is-at- $t_{1}$ bent" or, more elegantly, "Sam is $t_{1}$-ly bent" (see Johnston 1987, p. 129). So, according to adverbialism, there is not just the having of a property, there is always t-ly having (or having-at-t) of a property. This will provide a solution to the problem of temporary intrinsics, because Sam is bent at $t_{1}$ and straight at $t_{4}$, and so he has both the incompatible properties, but it has the former $t_{1}$-ly and the latter $t_{4}$-ly and this is how the threat of a contradiction is avoided.

There is one important difference between adverbialism and indexicalism: only the latter, but not the former, is compatible with the bundle theory. So where we always had the two options before, we have only one here. Indeed, in order to be able to be an adverbialist, the substratum theorist has the option to say that there are three components in her view - a substratum and its properties, of course, but also a third theoretical device: a relation of exemplification between the substratum and its properties, which, one can claim, is time-indexed (rather than the properties being time-indexed, as the indexicalist would have it). The endurantist-adverbialistsubstratist picture then looks like this:

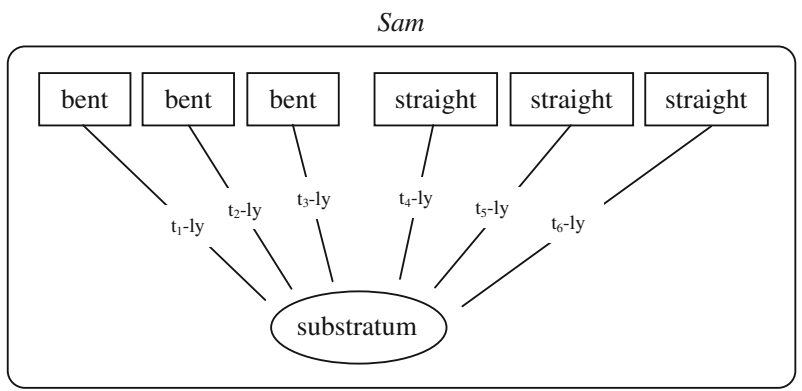

The bundle theorist, obviously, cannot (and does not want to) provide anything like this, since she does not introduce a substratum that needs to be related by a special relation to its properties; her view does not require any such intermediaries 
(and so, she cannot be an adverbialist since there is no suitable place where to put the adverbialist index ${ }^{9}$ ). Note that this holds only for a certain version of the substratum theory, namely a version that insists on there really being this third component in the theory, a (time-indexed) relation between the substratum and its properties. And even substratum theorists themselves often agree that this is a bad version of their view (among other reasons, because of Bradley-like regresses and related issues). Most recently, Ted Sider (2006) in his defence of substrata insists that the relation of exemplification should not be put too much weight on, and elsewhere it is often claimed as well that exemplification is not a relation, that it is a "non-relational tie" that we should not reify exemplification (Lewis 1983, pp. 351355). If the friend of substrata follows these recommendations, then she will hardly be able to be an adverbialist, since there would be no good place to put the adverbialist index on anymore. But if she is not impressed by the troubles that arise when one takes the relation of exemplification seriously as a relation (that one can put an index on), then she has the option of being an adverbialist, which gives rise to the endurantist adverbialist substratist view.

Now we have this precise view in mind, let us see how it behaves with respect to the four steps 1-4 from Sect 2.5 above:

1. As it was the case for endurantist indexicalism and for the perdurantist worm view, adverbialism also has to use a temporalizing device (" $t_{n}$-ly") in order to be able to say that Sam is bent or straight, and as the other views it cannot say that Sam is bent or straight simpliciter.

2. Since adverbialism also is an eternalist view, and as the schema above shows, it also has to (and can) equally face the 'no-change objection', for the same reasons given in the case of indexicalism.

3. As the two other views, adverbialism also implements the notion of a temporal part (and can thus handle the case of the depicta of photographs in the same way).

4. As the two other views, by using the notion of a temporal part adverbialism can equally well provide a satisfactory treatment of puzzle cases involving coincidence such as the Statue and Lump case.

The last two points are easily seen by examining the endurantist adverbialist substratist schema for the case of the Statue and Lump:

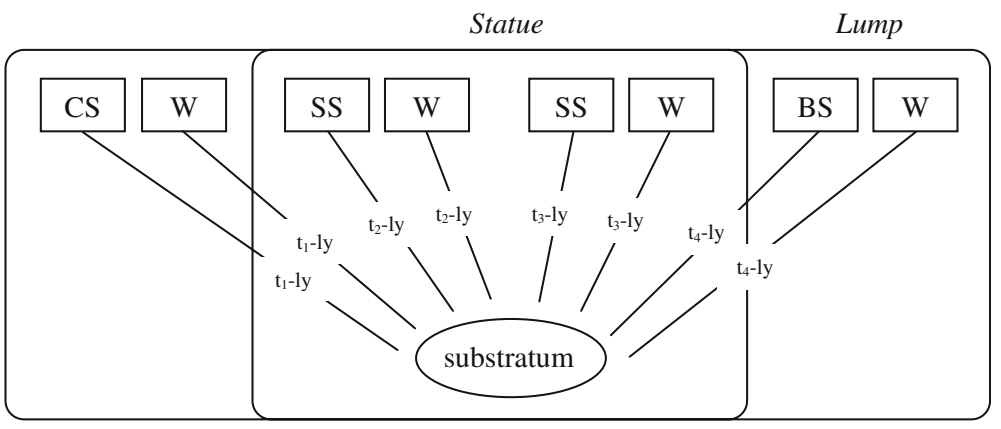

\footnotetext{
${ }^{9}$ Indexing the bundling relation would make it straightforwardly a perdurantist view.
} 
Thus, once we have this precise and correct picture in mind, the endurantist adverbialist eternalist substratist view turns out not to be different from the perdurantist worm view and the endurantist indexicalist view with respect to the four steps examined above.

As far as the differences are concerned, this version of endurantism is different from the perdurantist worm view for the same two reasons mentioned at the end of Sect. 2.5, and in addition to that there is the further difference between endurantism and perdurantism here which is that only the latter is compatible with the bundle theory.

\section{Part II: The Stage View: A Common Enemy?}

\subsection{Point 9}

Finally, I now turn to an eternalist theory of persistence through time that is different from the other three views with respect to the four steps examined above: the perdurantist stage view. I shall first go through the four steps, and then ask what kind of difference we are dealing with here: metaphysical, or purely semantic/ linguistic?

The stage view's account of persistence and change over time is the following (I use the bundle theory, but like in the case of the worm view and of endurantist indexicalism and unlike in the case of adverbialism, using the substratum theory would make no relevant difference here):

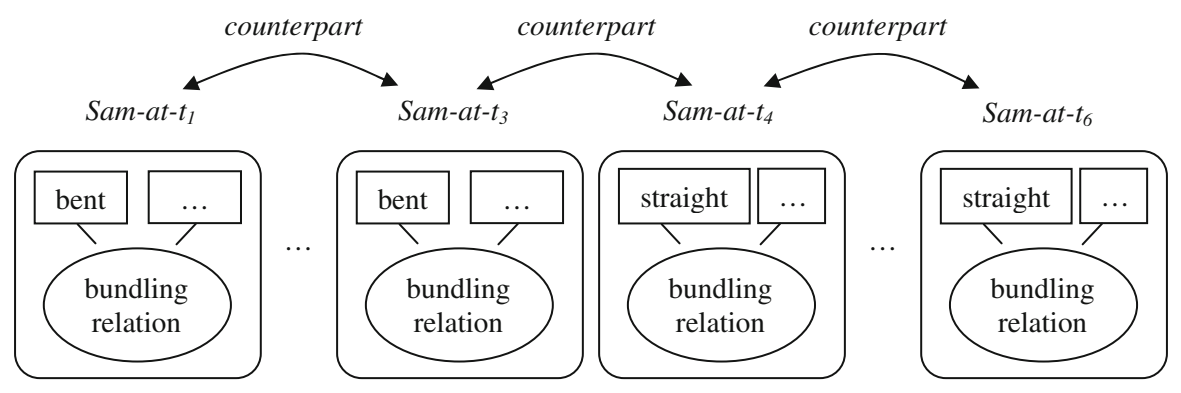

According to this view, a person like Sam exists only at one time and is an instantaneous entity (an instantaneous 'stage'), and it persists through time by having different temporal counterparts at other times. The ordinary object we refer to as Sam is not a four-dimensional (temporally extended) entity, rather, there is a series of stages interconnected by a counterpart relation, and ordinary objects are conceived of as being the stages rather than the whole composed of them. Strictly speaking, the different Sams are only momentary entities but they are nevertheless said to persist through time by having counterparts at other times. However, the stage view is still a four-dimensionalist view since it does not deny the existence of temporally extended objects - the four-dimensional entities that are aggregates of 
stages - they exist as well as the stages do. It's just that, according to the stage view, the objects we ordinarily name and quantify over are stages rather than worms. Let us now see how the stage view behaves with respect to the four steps 1-4 above.

The first point of departure from the three other views is already easily seen when it comes to the having of temporary intrinsic properties simpliciter. The stage view, unlike the perdurantist worm view and the two endurantist views, can guarantee the having of temporary intrinsic properties simpliciter by ordinary objects themselves. This is easily achieved since, according to this view, ordinary objects like Sam (-at$t_{1}$ ) are (instantaneous) stages, and those can have properties simpliciter without making them to be relations to times. So such a view allows Sam to have simpliciter the property of being bent (in a non-derivative way, contrarily to what the worm view has to say).

What about the second step, the 'no-change objection'? It seems that here also, the stage view behaves differently than the three other views- the fact that it appeals to different counterpart-related objects to provide an account of persistence makes it weaker against the objection. Let us remember shortly how it goes: perdurantism (worm view) does not account for genuine change of persisting material objects like Sam, because it tells us a story about different objects (his different temporal parts) existing at different times and having different properties, but none of those objects can change. And similarly for endurantism (take the indexicalist version here): the fact that Sam has the property of being-bent-at- $t_{1}$ is eternally (always) true and can never change; indeed, any property that Sam has, he has it always and forever, and so he has at a time $t_{1}$ the very same properties that he has at a later time $t_{2}$, and so, the 'no-change objection' goes, he does not undergo genuine change.

As I already mentioned above, and as many have argued, I don't think that either of these views has really anything to fear here, since all have an equally adequate reply to the objection. In short, here it is: the perdurantist can say that there is something that changes, namely the four-dimensional Sam who is composed of all of his temporal parts. Once one of his parts has any intrinsic property, it cannot change, and it will always be true that it has (tenselessly) this property, but the fourdimensional entity can be said to undergo a change by having different parts at different times. Change is simply the having of different properties at different times, and the perdurantist's worm can easily accommodate this claim. And so can (obviously) the endurantist.

But if one endorses the stage view, such a reply seems unavailable-for there is no one thing that ever has the different properties. The worm view theorist claims that the temporally extended Sam has them in a derivative way, and the endurantist claims that he has different time-indexed properties, or that he has them $t_{n}$-ly, but the defender of the stage view does not have room for any of this in his theory: she cannot show anything that could be said to undergo a change, even in a derivative way. Of course, she can say that a certain stage, say at $t_{1}$, is $\mathrm{F}$ and will be $\neg \mathrm{F}$ at $t_{2}$ in virtue of being a temporal counterpart of another stage existing at $t_{2}$ that is $\neg \mathrm{F}$. This could maybe sound like a solution, but it is not: for these two stages are just two completely different things. As Mellor (1998, p. 89) puts it, "change needs identity as well as difference". But there is only difference in the stage view, there are only different things with different properties. 
This is not the end of the story, of course. For what is involved here, and what the stage view theorist's reply will criticize, is a version of the 'Humphrey objection' applied to temporal counterpart theory. The objection runs as follows: if Sam says now that he will visit his friend Worf tomorrow, then the sentence turns out to be true iff he'll visit Worf tomorrow. But this is, according to the stage view, simply impossible, because the person who says now that he'll visit Worf tomorrow is a stage, a momentary entity that will not itself persist until tomorrow and thus, will not be able to visit anyone. Sam, the person who is doing the speaking, is simply not identical, in any sense, to the person who's supposed to do the visiting. Granted, Sam has a counterpart tomorrow that'll visit (or not) Worf. But whatever the counterpart relation is, it is not identity. So, the objection goes, if Sam says he'll visit Worf tomorrow, why would Worf care about someone else, similar to Sam and linked to him by a counterpart relation, to visit him? Note that the "someone else" claim is very strong here: if one endorses the stage view, there is no sense in which Sam from today is identical to Sam tomorrow. If one generalizes this objection, one can simply claim that it denies persistence altogether. For the stage view ontology provides us only with instantaneous entities, and aggregates of those, but it rejects 'worms' in the sense that it rejects the view that ordinary objects like people are four-dimensional entities. The stage view's persistence, the objector says, is not genuine persistence.

Sider defends the stage view against this objection as follows: "[It] is wrong to say that the stage view denies that 'You will do it' means that you will do it. 'Ted was once a boy' attributes a certain temporal property, the property of once being a boy, to me, not to anyone else. Of course, the stage view does analyse my having this property as involving the boyhood of another object, but I am the one with the temporal property, which is the important thing. The stage view is consistent with stages having temporal properties; it's just that temporal properties are given a counterpart theoretic analysis" (Sider 2001a, p. 195).

But this reply is not likely to give satisfaction to the objector. Granted, the stage view is consistent with stages having temporal properties, but not the ones we want. To take Sider's example, if we say "Ted was once a boy", we are ascribing a certain temporal property to Ted (who exists now). But if we want to endorse the stage view, it is not the property of "once being a boy", but rather, the property of "once there being a counterpart of Ted that is a boy". If the stage view theorist allows these two properties to be equivalent then she is mistaken-for if it is the former that we ascribe to Ted, it is solely about Ted that we are speaking, but if we ascribe him the latter, we are speaking about Ted and someone else, and that makes all the difference. Sider's response can only appear to be satisfactory if one takes the expression "once being a boy" to be a suitable paraphrase of the expression "once there being a counterpart of $\mathrm{x}$ that is a boy", but such a strategy, objectors like Sally Haslanger will claim "strains the limits of credibility" (Haslanger 2003, p. 337).

Although I have sympathies with the objector, my point here is not to claim that we should reject the stage view because of this objection. Rather I only wish to claim that the stage view has more to do than the worm view or any of the versions of endurantism in order to answer the no-change objection step (2), and that its reply has to be different, since it cannot appeal to any one object having different properties at different times, in the way the two other views do it. 
With respect to step (1), the stage view has an advantage over the other competing views, and with respect to step (2), it seems on the contrary to be in a weaker position. This should not be very surprising, since the stage view is also structurally different from its competitors (this is step (3)). As we have seen, according to the stage view, a person like Sam is 'no more' than this:

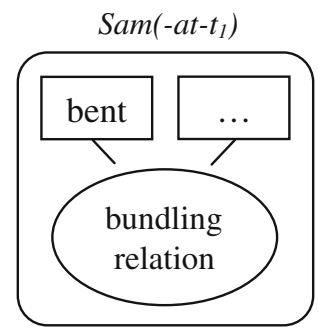

Which is quite different from the worm view and both versions of endurantism. To put it simply, the three other views claim that Sam is 'bigger'- he is a bundle ${ }^{10}$ not only of properties he has at one time, but of all of his properties he ever has. And this salient difference in structure will also make the stage view to behave very differently with respect to step (4): the case of the Statue and the Lump. While the crucial notion that is appealed to by the worm view and endurantism to have a treatment of the puzzle is the notion of overlap, nothing similar is either available or needed if one embraces the stage view, since there is nothing temporally extended that could be said to overlap. At a time $t_{2}$ for instance, there is only one instantaneous entity that is a statue made out of a lump of clay but there are not two coincident objects at this time, since the reason for thinking that there could be two different objects was that they were suspected to have distinct historical properties like "being cube-shaped in the past" or "having existed at $t_{1}$ ", but no instantaneous entity has any such properties. It can be said to have them by having different temporal counterparts at different times, but the counterpart relation being flexible (context dependent) it will be able to have different counterparts qua Statue and different counterparts qua Lump-so what we have is just one object that has different counterparts under different counterpart relations and there is no threat of ending up with coincident entities.

To sum up: the stage view is different from the three other views with respect to all four steps of my argument. It behaves better in the case of the having of temporary intrinsic properties, it is weaker with respect to the no-change objection, it is structurally different, and it provides a different treatment of the Statue and Lump case.

The diagnostic of why exactly this view is different from the others is readily at hand: because it takes objects like Sam to exist at only one single time, while all the competing views take them to exist at more than one time. To put it in a more objection-like way: because instead of providing an account of persistence through time, it actually denies genuine persistence.

\footnotetext{
${ }^{10}$ In the case of endurantist adverbialism, the substratum theory would be needed, which would not make any relevant difference to my present concerns.
} 
One way to support this objection is to insist on the importance of the fact that the stage view is weaker with respect to the no-change objection, as we have seen above, and to insist that the 'Humphrey objection' to temporal counterpart theory succeeds. But there is also another (but related) way to see this defect of the stage view: that the view does not allow ordinary objects to do the things they typically can do. People, like Sam, are stages. But stages are instantaneous entities, they do not have temporal extent. The unwelcome consequence of this is that people cannot do many of the things we would expect them to be able to do. For instance, it seems that a person should normally be able to utter a sentence. But, on the stage view, this turns out to be impossible, strictly speaking: the utterance of a sentence takes some time and a stage does not last long enough to make such a performance. Or, normally, Sam can run, but again, not according to the stage view; strictly speaking nobody can run because a person is an instantaneous entity and running takes time.

The obvious reply of the stage view theorist to this is that Sam can utter a sentence and run because he has counterparts at 'neighbour' times and if we take several counterparts together, they can achieve such a performance. It takes more than one single stage to speak or to run.

But then, what do we really mean when we say that a person runs? What do we refer to by "this person"? We have seen that it seems that if we refer to the instantaneous stage (as we should, if we follow Sider's recommendations: spacetime worms "are not ordinarily named or quantified over" Sider 2001a, p. 191) it is impossible for our sentence to be true (an instantaneous entity does not have enough time to run).

Then maybe we refer to a sum of successive person-counterparts, which is a thing that lasts long enough to do the performance. But what is this sum? I see two possibilities: first, that it is a set of numerically distinct entities (the distinct temporal counterparts), or second, that it is a whole composed of the different counterparts. The first possibility seems really unpalatable: the view according to which a set of distinct objects can run would be hard to defend. We are then left with the second possibility; but this just amounts to embracing the worm view, for the thing that has the properties we are interested in (running, speaking, and so on) is a temporally extended four-dimensional entity - and so, those properties are really had by a 'worm' rather than by a stage. So, since this way out (a way that nobody takes, as far as I know) is closed, the stage theorist will have no choice but stick to his original claim: "this person" refers to an instantaneous stage, and it has the property of running in virtue of having temporal counterparts at neighbour times-and this is how a person can run. Very well but what this claim commits the stage view theorist to, is to endorse the further claim that since the person has the property of running in virtue of its relations to other persons (his past and future counterparts), this property turns out to be extrinsic, contrary to what we'd usually say. And for the same reasons, a lot of properties that we usually take to be intrinsic, turn out to be extrinsic, according to the stage view. So if one wants to account for the fact that people can speak and run, and that the properties involved here are intrinsic, one should embrace the worm view or endurantism rather than the stage view.

Again, this is not the end of the story. For the stage view theorist will defend his view here by simply biting the bullet and accepting that most properties we thought 
to be intrinsic are in fact extrinsic. ${ }^{11}$ But, again, my point is not here to establish whether we should accept the stage view or not, although I have been offering reasons that point towards rejecting it. The point I wish to make by raising the objections above is to show in what respects the stage view is different from its competitors, and I think that this has been established.

Still, one might wonder what kind of difference this really is. Is it a metaphysical difference? It certainly is not a difference in what there is since all the views are eternalist and postulate the existence of the same distribution of matter across spacetime, and the stage view does not deny the existence of mereological sums of stages that correspond to the worm view's space-time worms. ${ }^{12}$ So the difference is not one in what there is (contrary to what is the case in the presentism-eternalism controversy), but in the analysis of what ordinary objects like tables or people are. Is this a metaphysical or a semantic difference? In a sense, as Sider himself claims, it seems to be an only semantic/linguistic one, since the disagreement only seems to be about ordinary language terms and reference - a disagreement located in what we usually name and quantify over when we make claims about ordinary objects.

But, as Parsons (2004, p. 3) points out, rightly I think, metaphysical questions are not only questions about what there is, but also about how things are. To take his example: "Does time pass?" is as much a metaphysical question as "Does the future exist?" It is true, Parsons says, that the worm view and the stage view agree on the stuff there is, but it doesn't follow that they agree on all metaphysical questionslike the question of what the nature of tables and people is, that is, how they are. The question whether, for example, I am three or four-dimensional is a metaphysical one. Or, the two views do not provide the same answer to the question: "how many people are there on the photograph of Sam?"-indeed, there are mисh more people on this photograph according to the stage view (as many as there are instants, or infinitely many if time is continuous) than according to what the other views say. So it seems that the disagreement between the stage view and the other competing views I have discussed is not merely semantic/linguistic but genuinely metaphysical, and that it is about whether ordinary objects are best conceived of as timebound (momentary) or extended in time.

Acknowledgments For very valuable comments and suggestions, I would like to thank Michael Esfeld, Fabian Dorsch, Mark Heller, Laurie Paul, and Gianfranco Soldati, as well as the participants to the SOPHA Conference in Aix-en-Provence. The photograph included in this paper is protected by international copyright by Jiri Benovsky, www.benovsky.com.

\section{References}

Benovsky J (2008) The bundle theory and the substratum theory: deadly enemies or twin brothers? Philos Stud 141:175-190

\footnotetext{
11 Both Ted Sider and Achille Varzi do accept this consequence of the stage view (personal communications, 2005); see also Sider (2001b).

12 Besides, it is likely that whatever the temporal counterpart relation is, it twill turn out to be the same as the 'glue' relation that unifies the temporal parts of a single space-time worm.
} 
Haslanger S (2003) Persistence through time. In: Loux M, Zimmerman D (eds) Oxford handbook of metaphysics. Oxford University Press, Oxford

Johnston M (1987) Is there a problem about persistence? Aristot Soc 61:107-135

Lewis D (1983) New work for a theory of universals. Aust J Philos 61:343-377

Lewis D (1986) On the plurality of worlds. Blackwell, Oxford

Lewis D (2002) Tensing the copula. Mind 111:1-13

Mellor DH (1998) Real time II. Routledge, London

Parsons J (2004) Review of 'four-dimensionalism' by Theodore sider. Philos Q 54:188-191

Paul L (2002) Logical parts. Noûs 36:578-596

Paul L (2006) Coincidence as overlap. Noûs 40:623-659

Prior A (1996) Some free thinking about time. In: Copeland J (ed) Logic and reality: essays on the legacy of Arthur Prior. Oxford Clarendon Press, Oxford

Sider T (2001a) Four-dimensionalism. Clarendon Press, Oxford

Sider T (2001b) Maximality and intrinsic properties. Philos Phenomenol Res 63:357-364

Sider T (2006) Bare particulars. Philos Perspect 20:387-397

Simons P (2000) How to exist at a time when you have no temporal parts? The Monist 83:419-436

Van Inwagen P (1981) The doctrine of arbitrary undetached parts. Philos Q 62:123-137

Van Inwagen P (1985) Plantinga on trans-world identity. In: Tomberlin J, Van Inwagen P (eds) Alvin plantinga: a profile. Reidel, Dordrecht, pp 101-120 